\title{
Discrete subvalvar aortic stenosis after tetralogy of Fallot repair
}

\section{CYNTHIA CHRISTY, JACQUELINE A NOONAN, WILLIAM N O'CONNOR}

From the Departments of Pediatrics and Pathology, University of Kentucky Medical Center, Lexington, Kentucky, USA

SUMmARY A 6 year old girl developed severe subvalvar aortic stenosis after repair of a typical Fallot's tetralogy at the age of 9 months.

The development of discrete subvalvar aortic stenosis after repair of Fallot's tetralogy is most unusual and prompts this report.

Kelly et al., 1 in 1972, divided discrete subaortic stenosis into two distinct types. Type I is a 1 to $2 \mathrm{~mm}$ thick discrete membrane immediately under the aortic valve and type II is a thicker membrane $1 \mathrm{~cm}$ below the valve consisting of a fibrous ring and associated with muscular obstruction of the left ventricular outflow tract. Discrete subaortic stenosis is a progressive disease and there is some evidence that it may develop after birth. ${ }^{23} \mathrm{Up}$ to $57 \%$ of patients have associated cardiac defects. ${ }^{2}$ The association of left sided obstructive lesions with Fallot's tetralogy is rare. The few reports of subaortic stenosis with Fallot's tetralogy have emphasised outflow obstruction from abnormalities of the mitral leaflets and chordae. ${ }^{4}$ We are aware of only one published case ${ }^{5}$ of discrete subvalvar aortic stenosis in a patient with Fallot's tetralogy similar to the patient to be reported.

We recently treated a 6 year old girl who developed subvalvar aortic stenosis after repair of Fallot's tetralogy at 9 months of age. Preoperative cardiac catheterisation had shown fairly severe infundibular stenosis and a right to left shunt through the ventricular septal defect. There was no evidence of left ventricular outflow obstruction. At operation, excess infundibular muscle was excised, a patent foramen ovale was closed, and a large subaortic ventricular septal defect repaired with a woven Teflon patch. She did well after operation until 6 years of age when she developed decreased exercise tolerance. Follow-up cardiac catheterisation was recommended because of symptoms and the development of a thrill and an increase in intensity of a murmur along the left sternal border. A grade 4 harsh ejection systolic murmur was heard along the left sternal border and a grade 1 diastolic blow at the right base. There was mild cardiomegaly on $x$-ray examination and an electrocardiogram showed sinus rhythm, with complete right bundlebranch block. Left ventricular voltage was increased compared with previous electrocardiograms, but left ventricular hypertrophy was not apparent.

At catheterisation, the right ventricular pressure was $32 / 10 \mathrm{mmHg}$, the left ventricular pressure was $220 / 14 \mathrm{mmHg}$, and aortic pressure was $96 / 56 \mathrm{mmHg}$, giving a $145 \mathrm{mmHg}$ gradient on pullback from the left ventricle to the aorta. Injection into the right ventricle showed no evidence of residual infundibular stenosis. A left ventricular injection showed an intact septum and a discrete subaortic linear lucency typical of a

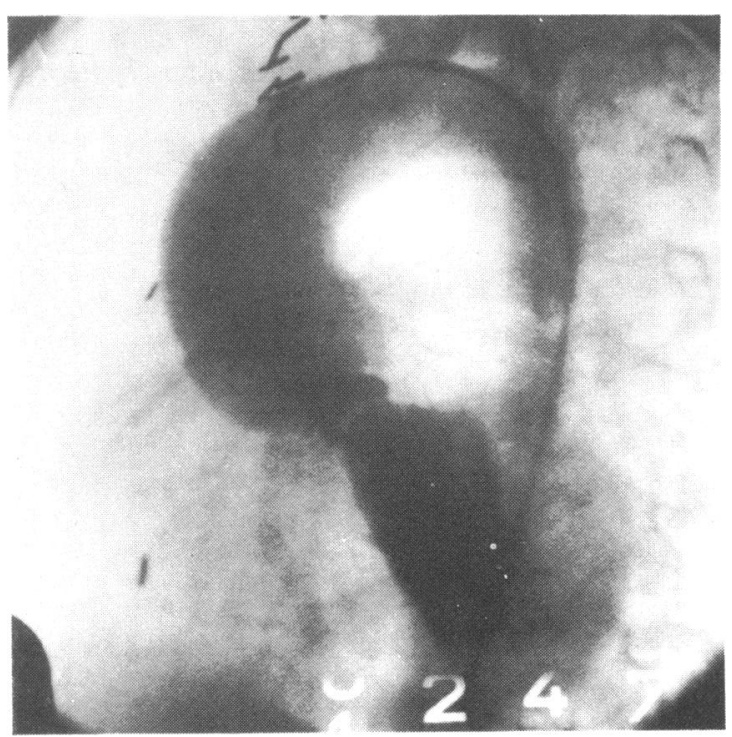

Fig. 1 Left ventricular cineangiogram showing subaortic membrane and dilated ascending aorta. 




(a)



(b) Fig. 2(a) Excised subaortic membrane. (b) Photomicrograph of resected specimen illustrating fibrous ridge on endocardium overlying irregular bundles of myocardium. (Elastic-trichrome stain, original magnification $\times 100$.)

subaortic membrane (Fig. 1). The aortic root injection showed dilatation of the ascending aorta and very mild aortic valve regurgitation.

M-mode echocardiography showed early systolic aortic valve closure, symmetrical hypertrophy of the septum and posterior left ventricular wall, and a small hypercontractile left ventricular chamber with mitral valve flutter. The right ventricular dimension and wall thickness were normal for age. A two dimen- sional echo showed a somewhat thick subaortic membrane.

At reoperation, a type 2 discrete fibrous membrane was noted (Fig. 2a). The borders of the membrane were made up of the muscular septum, the leading edge of the anterior leaflet of the mitral valve, and the bottom edge of the endothelialised ventricular septal defect patch. After resection of the membrane, moderate left ventricular outflow tract obstruction 
remained so that a subvalvar muscular ridge was identified and resected.

Histological examination of the subvalvar aortic membrane showed layered fibrous and myxomatous tissue. Sections of the myocardium showed hypertrophy with focal areas of myofibre disorganisation similar to that seen in classical idiopathic hypertrophic subaortic stenosis. In addition, there were some slitlike spaces resembling sinusoids noted between myocardial fibres (Fig. 2b).

Complete heart block developed postoperatively and a pacemaker was implanted. Three months later, sinus rhythm had returned and the patient has done well on follow-up.

\section{Discussion}

In this patient, the underlying myocardium showed muscular hypertrophy and disorganisation similar to that described previously by Beçu quoted in Somerville. ${ }^{6}$ He found that dysplastic myocardium identical to that found in hypertrophic obstructive cardiomyopathy was frequently present low in the ventricular septum of infants with mild fixed subaortic stenosis who had died of other causes. His findings stimulated Somerville $e^{6}$ to postulate that the abnormal septal muscle contracts abnormally, resulting in turbulence which stimulates the formation of a discrete subaortic stenosis. A recent report by Freedom et al.$^{3}$ supports this theory. It is interesting to speculate in our patient that the vetricular septal defect patch and complete right bundle-branch block may have stimulated a congenitally disorganised myocardium to form a dis- crete subaortic membrane. Unfortunately, we do not know if there was underlying dysplastic myocardium adjacent to the ventricular septal defect patch at the time of the original operation. If dysplastic myocardium is present in some patients with Fallot's tetralogy, one might expect more patients in the future to develop discrete subvalvar aortic stenosis after successful repair.

\section{References}

1 Kelly DT, Wulfsberg E, Rowe RD. Discrete subaortic stenosis. Circulation 1972; 46: 309-22.

2 Newfeld EA, Muster AJ, Paul MH, Idriss FS, Riker WL. Discrete subvalvar aortic stenosis in childhood: study of 51 patients. Am f Cardiol 1976; 38: 53-61.

3 Freedom RM, Fowler RS, Duncan WI. Rapid evolution from "normal" left ventricular outflow tract to fatal subaortic stenosis in infancy. Br Heart $\mathcal{F}$ 1981; 45: 605-9.

4 Nagao GI, Daoud GI, McAdams AJ, Schwartz DC, Kaplan S. Cardiovascular anomalies associated with tetralogy of Fallot. Am F Cardiol 1967; 20: 206-15.

5 Sanders JH Jr, Van Praagh R, Sade RM. Tetralogy of Fallot with discrete fibrous subaortic stenosis. Chest 1976; 69: 543-4.

6 Somerville J. Congenital heart disease-changes in form and function. Br Heart $\mathcal{F}$ 1979; 41: 1-22.

Requests for reprints to Dr Jacqueline A Noonan, Department of Pediatrics, University of Kentucky Medical Center, 800 Rose Street, Lexington, Kentucky 40536, USA. 